\title{
Estimation of Forest Canopy Cover and Forest Fragmentation Mapping Using Landsat Satellite Data of Silabati River Basin (India)
}

\author{
Biswajit Bera $^{1} \cdot$ Soumik Saha ${ }^{2} \cdot$ Sumana Bhattacharjee $^{3}$
}

Received: 14 May 2020 / Accepted: 11 October 2020 / Published online: 13 November 2020

(c) The Author(s) 2020

\begin{abstract}
Forest is an imperative part of environment but in the recent years, forest areas are being transformed due to population expansion, unscientific urbanization and a rising trend of industrialization in some countries. Dense forests habitats have been fragmented into patch forest region. This paper attempts to find out the forest canopy or crown density and forest fragmentation areas as well as to identify the spatiotemporal changing paradigms of forest within the Silabati river basin. Forest Canopy Density and fragmentation models are an important craftsmanship to examine the health of the forest or vegetation in a given area. Various indices such as Normalize Difference Vegetation Index, Advanced Vegetation Index, Shadow Index, Bareness Index and ultimately weightage overlay analysis methods have been adopted to determine forest health or anthropogenic stress on forest habitats. Higher weight has been assigned to dense forest areas and open forest area has been given lower weight. The result shows that forest canopy or crown cover as well as forest density are radically reduced in between the time period 1998 and 2009. It is also stated that the total $116.549 \mathrm{~km}^{2}$ areas have been degraded during 11 years period (1998-2009) with a rate of $10.59 \mathrm{~km}^{2} /$ year. Meanwhile, $180.02 \mathrm{~km}^{2}$ forest areas have been regained in between 2019 and 2009 with a rate of $18 \mathrm{~km}^{2} /$ year that is possible only due to implementation of forest policies exclusively execution of participatory or joint forest management techniques.
\end{abstract}

Keywords Forest canopy $\cdot$ Fragmentation $\cdot$ River basin $\cdot$ Joint forest management $\cdot$ Digital maps

\section{Schätzung der Waldüberschirmung und Waldfragmentierung mit Hilfe von Landsat- Satellitendaten des Silabati-Flussbeckens (Indien)}

\section{Zusammenfassung}

Der Wald ist ein grundlegender Bestandteil der Umwelt, aber in den letzten Jahren werden Waldgebiete aufgrund von Bevölkerungswachstum, unwissenschaftlicher Urbanisierung und einem steigendem Trend der Industrialisierung in einigen Staaten verändert. Die Lebensräume der dichten Wälder wurden in den Forstregionen fragmentiert. Dieses Papier versucht, die Waldkronen oder Kronendichte und Waldfragmentierungsgebiete zu finden sowie die räumlichzeitlich wechselnden Paradigmen des Waldes innerhalb des Silabati-Einzugsgebiets zu identifizieren. Forest Canopy Density (FCD) und Modelle

Sumana Bhattacharjee

sumana.aarohi@gmail.com

Biswajit Bera

biswajitbera007@gmail.com

1 Department of Geography, Sidho-Kanho-Birsha University, Ranchi Road, P.O. Purulia Sainik School, Purulia 723104, India

2 Bankura, West Bengal, India

3 Department of Geography, Jogesh Chandra Chaudhuri College, Calcutta University, 30, Prince Anwar Shah Road, Kolkata 700 033, India 
zur Fragmentierung sind wichtige methodische Ansätze, um die Gesundheit des Waldes sowie der Vegetation in einem bestimmten Gebiet zu untersuchen. Verschiedene Indizes wie Normalize Difference Vegetation Index (NDVI), Advanced Vegetation Index (AVI), Shadow Index (SI), Bareness Index (BI), und letztendlich wurden auch Methoden zur Analyse der Gewichtsüberlagerung eingeführt, um die Gesundheit der Wälder oder die anthropogene Belastung der Waldlebensräume zu bestimmen. Dabei wurde den dichten Waldgebieten eine höhere Bedeutung zugewiesen, und die offene Waldfläche wurde weniger gewichtet. Das Ergebnis zeigt, dass Waldkronen oder Kronenbedeckungen sowie die Walddichte zwischen 1998 und 2009 radikal reduziert wurden. Ferner wird festgestellt, dass die Gesamtzahl von $116.549 \mathrm{~km}^{2}$ an Gebieten während des Zeitraums von 11 Jahren (1998 bis 2009) mit einer Rate von $10.59 \mathrm{~km}^{2} / \mathrm{Jahr}$ abgebaut wurde. Inzwischen wurden zwischen 2009 und 2019 180,02 km² Waldflächen mit einer Quote von $18 \mathrm{~km}^{2}$ pro Jahr wiedergewonnen, was nur durch die Umsetzung der Forstpolitik ermöglicht wird, die ausschließlich die Durchführung partizipatorischer oder gemeinsamer Waldbewirtschaftungstechniken durchführt.

Schlüsselbegriffe Walddach · Fragmentierung · Flusseinzugsgebiet · Gemeinsame Waldbewirtschaftung · Digitale Karten

\section{Introduction}

Forest means a large tract or land which is covered by trees, underbrush and woodland. Similarly, a large number or dense mass of vertical or tangled objects which is dominated by trees; it may be a few $\mathrm{km}^{2}$ to thousands of $\mathrm{km}^{2}$. The forests include equatorial, tropical deciduous, tropical evergreen forest, tropical rainforest, Mediterranean, temperate broad-leaved deciduous and mixed warm temperate broadleaved deciduous, and coniferous. Forest is completely an indispensable renewal resource since the dawn of the human civilization. Oxygen, the most inevitable ingredient for human being, is manufactured from the forest. It has great ecological and economic significances. Approximately, onethird of world population directly or indirectly depends on forests for different purposes such as domestic, industrial, sports, and medical. The primitive people lived with harmony in nature. But the degradation or elimination had been started from evolution of modern industrial civilization. The high rate of depletion has been started after 1650 due to high population explosion, urban and rural growth along with their daily demand of food, fiber and fuel. Forest cover also indicates the sustainability of an area and also reveals the natural health stipulation of an area. It is very significant for us to find out the spatiotemporal change of forest cover with relation to human intervention. According to Indian state forest report 2011, India totally contains $24 \%$ forest area of its total land mass and state of Madhya Pradesh has the largest forest cover area in India and Meghalaya has the highest forest density. Vegetation density and canopy cover may create an equilibrium condition in eco-system or broadly in the ecosphere, but due to some illegal anthropogenic activities, forests are being damaged in large scale day by day (Kayet et al. 2016). In the recent years, forests are being degraded by industrial and agricultural revolution, so appropriate scientific land-use planning is indispensable for forest resource conservation (Crist and Cicone 1984). Ecosystem health or largely environmental health is determined by the presence of biota in a particular terrestrial biome (Jelaska 2009). Forest Canopy Density (FCD) model is a fundamental apparatus to comprehend the forest crown condition of an area and it helps us to take decision for sustainable forest management (Coppin and Bauer 1994; Sahana et al. 2015). With the advancement of science and technology along with remote sensing and geographical information system techniques, the spatial forest health or forest condition of an area can be detected (Guhathakurta and Roy 2000). According to 1986 forest policy, a RS-GIS cell should be set up in every state of India to monitor the forest degradation rate (Raha et al. 1997). Multi-temporal, multi-spectral and hyper-spectral images recognize the vegetation property and vegetation phenology (Zhang et al. 2003). Using wild-field sensor data, Normalized Difference Vegetation Index is done to separate different types of vegetation (Singh et al. 1999). Various types of satellite images with different sensors (Thematic Mapper, Enhanced Thematic Mapper, and Linear Imaging Self Scanning-I/II/III/IV) have also been used in case of multiple Normalize Difference Vegetation Index (NDVI) and FCD study of the world (Maselli et al. 1995). In the last decade, sustainable utilization of forest land and scientific management techniques are very much feasible to reduce the rate of forest degradation (Beaulieu et al. 2016). Today many developing countries have monitored the spatiotemporal changing patterns and phenomenal growth of forest through Forest Canopy Density (FCD) model (Rikimaru 1997). Rikimaru was first used FCD model by thematic mapper data, but recently it is widely used to audit forest health and deforestation. Similarly, it is vastly applied in the tropical forest areas to estimate the forest land degradation as well as afforestation rates within the forest and in the forest buffer (Azizi 2008). Forest fragmentation index tool on GIS platform was first developed by Center for Land use Education and Research (CLEAR) in 2002, and it was modified in 2009. Forest fragmentation tool in GIS platform may take a momentous role to forest management and sustainable conservation of forest habitat system (Reddy 2013). 
If forest habitats are fragmented, the hunting, gathering as well as poaching activities are simultaneously amplified (Lin 2014) and result equilibrium mechanism of ecosystem will be diluted. Various studies divulge that the anthropogenic stress on forest land and population explosion in developing and under-developed countries are principal regulating factors behind high rate of forest fragmentation in the last 3 decades. According to Food and Agricultural Organization (FAO), India occupies 68 million ha of forest in 2010, and future trend shows positive signal.

According to report of 2018, total forest cover in India has been increased by $802,088 \mathrm{~km}^{2}$. On 30 December 2019 , Indian forest report showed that the greeneries including plantation areas have been enlarged by $3796 \mathrm{~km}^{2}$ and now India has $25 \%$ forest areas in compared to its total land mass. This valuable forest resource plays a significant liability to ameliorate the total GDP of the country. Today, FCD model has been preferred to implement almost all parts of the globe while Portugal, Nepal, Australia and also Philippines have used very recently to inspect the spatial health and density of the vegetation (Panta and Kim 2006; Wang and Brenner 2009; Hasmandi et al. 2011). A dense forest becomes sparse due to continuous human stresses such as human encroachment, habitat destruction for shelter and industry and conversion of forest land for agriculture. The highresolution remote sensing and satellite images facilitate to identify these vulnerable forest hotspots (Saei Jamalabad and Abkar 2000). A recent study indicates that the binary logistic regression (BLR) model is more appropriate and rational technique to predict the magnitude of deforestation of a region (Bera et al. 2020).

In this present scientific study, different indices such as NDVI, Advanced Vegetation Index (AVI), Bareness Index (BI), and Shadow Index (SI) have been used to show the spatial pattern of Forest Canopy Density using Operational Land Imagery (OLI) images with $30 \mathrm{~m}$ spatial resolution and tried to make the study more relevant in the recent day context. Different multi-temporal data (1998, 2009 and 2019) have been used to show the fragmentation pattern of the study area. In this context, the primary hypothesis of the study is why in the recent years forest fragmentation as well as forestland conversion is rapidly increasing at the proximity of regional growth points? Another relevant research question has been raised that the how much anthropogenic stress is replicated within the river basin? The authors have tried to identify the canopy cover status and also forest fragmentation of Silabati river basin to make the study useful for sustainable forest management. The main objectives of the study are (1) to identify the canopy cover density within the Silabati river basin and (2) to find out the forest fragmentation areas or hotspots through the evolution of time.

\section{Study Area}

Silabati river is also known as Shilai which originates from Hura block, Purulia district, West Bengal and the river flows to south-westerly direction and joins with river Dwarakeswar near Ghatal. The combined flow of Dwarakeswar and Silabati is known as Rupnarayan and finally it falls in river Hooghly. Silabati river system is also a part of Ganga river system. This river flows through three districts of West Bengal mainly Purulia, Bankura and Paschim Midnapur. The area lies between $22^{\circ} 36^{\prime}$ to $23^{\circ} 12^{\prime}$ North latitude and $86^{\circ} 38^{\prime}$ to $87^{\circ} 43^{\prime}$ East longitudes (Fig. 1) and the whole basin contains approximately $3390 \mathrm{~km}^{2}$.

The upper course of this basin has a multiple topographic impressions with respect to lower section (Fig. 2). The upper course of the basin is characterized by very undulating surface whereas lower course is composed by plain topography with isolated lateritic soil pockets (Shit and Maiti 2012). The upper and middle courses of the river basin have high lateritic concentration and hydro-geologically, these areas are also characterized by high-iron $(\mathrm{Fe})$ content, high leaching capacity and also low water-holding capacity (Ghosh and Guchhait 2015). Dry monsoon deciduous forest is concentrated over the middle and lower sections of the river basin. Meanwhile, higher abundance of population is found in the lower course of the basin. Land degradation processes are very much active in the entire Silabati river basin. Subsequently, the middle and lower reaches are more vulnerable with respect to the upper reach (Mahala 2019). The extensive rill and gully erosion are one more significant hydro-geomorphic characteristic in the middle and upper reaches whereas gully is being accelerated towards the head (Shit and Maiti 2012). Ghatal and Khirpai Township areas are the high flood susceptible zones because almost every year, people are experiencing devastating flood hazard due to strategic geographical locations and unscientific human intervention within the river valley. Pre-Cambrian granitic gneiss and schist are confined in the upper part of the basin (Dolui et al. 2014). Unclassified crystalline rocks mainly gneiss and schist are dominated in the upper course of the basin area while younger alluvium is conquered in lower section of the basin due to gradual accumulation of quaternary alluvium (Mahala 2019). The lower portion of the basin is an extensive flood plain area with some densely inhabited places of Paschim Midnapur district such as Ghatal, Khirpai, Mulgram, Chandrakona, and Suratpur. Ghatal town is situated within the very high flood-prone region. The crop rotation along with interculture is being experienced by the inhabitants. The high density of population along with rapid settlement growth accelerates the high probability of deforestation in the middle and lower parts of watershed (Mahala 2019). In recent years, people choose to farm different types 

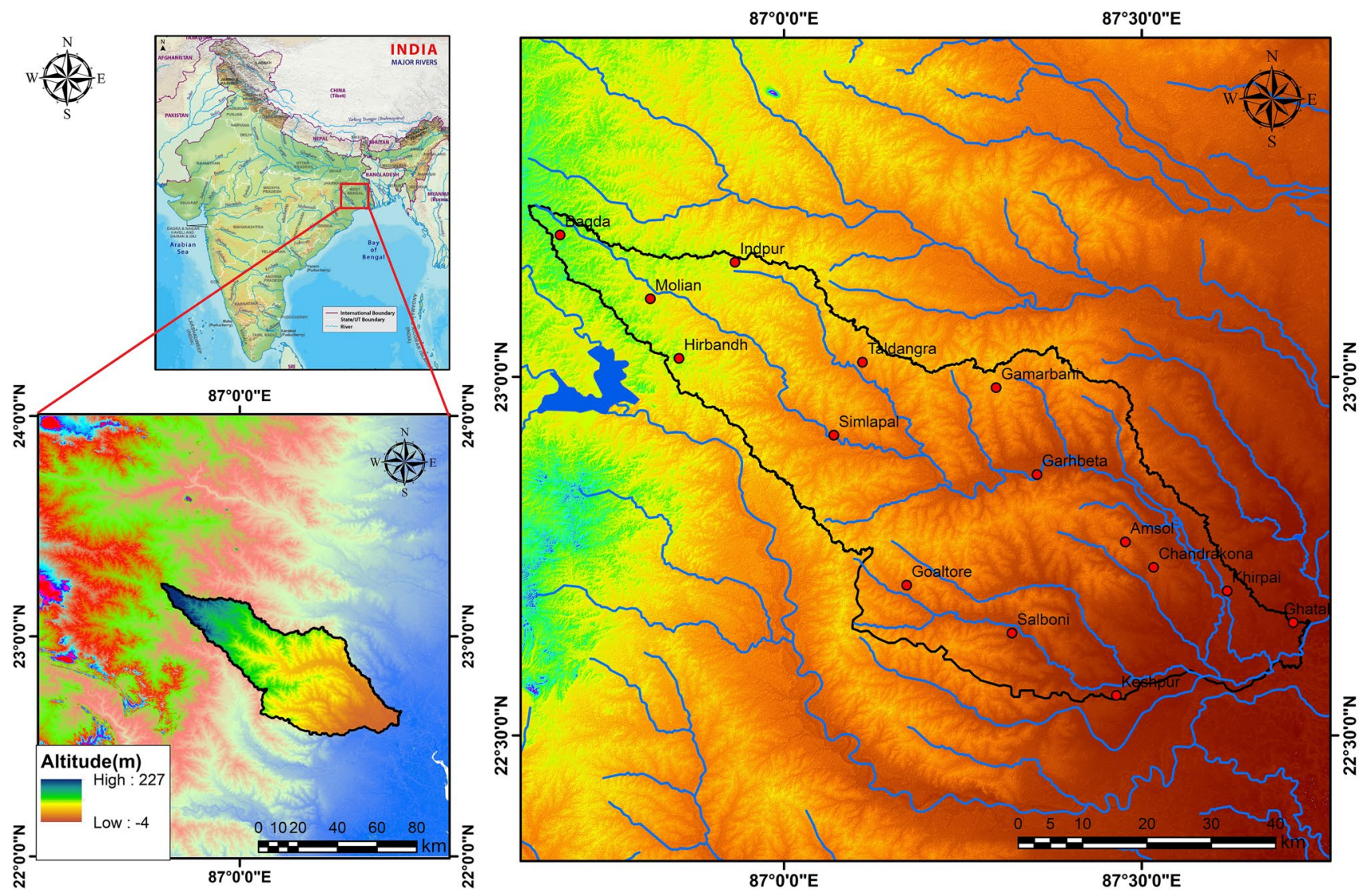

Fig. 1 Geographical location of the study area

of cash crops such as oil seed and pulses, along with animal husbandry which increases the high rate of deforestation at the vicinity of regional growth centers.

\section{Materials and Methods}

\subsection{Dataset}

Different types of hyper-spectral and multi-spectral with high spatial resolution satellite imageries such as Operational Land Imager (OLI) and Thematic Mapper (TM) have been used (Table 1) to estimate the status of Forest Canopy Density and rate of forest fragmentation of Silabati river basin. This satellite images have been obtained from United State Geological Survey website (http://earthexplorer.usgs. gov/) for extracting four different indices such as NDVI, BI, AVI, and SI. First, significant weightage values are assigned for different classes of multiple themes and FCD map has been prepared. It has been observed that the tropical monsoon deciduous forest has highest canopy growth during the months of August, September and October. The specific (date and time) satellite images have been acquired to get the better accuracy.

\subsection{Image Pre-processing}

Various Landsat images (Table 1) (with different sensors and time) have been collected from USGS earth explorer website to assess the spatiotemporal growth of forest canopy as well as different forest attributes of the study area. Predominantly monsoon and retreating monsoon images have been used to conduct the scientific forest research for sustainable forest resource conservation. Images are further converted into Universe Transverse Mercator (UTM) projection from geographical coordinate system for calculating the area and better extraction of data. WGS84 datum system has been considered during image-processing time. Atmospheric correction has been done in Erdas Imagine software (version: 16.5) for better representation of satellite images and data acquisition. Meanwhile, the proper band combinations have been chosen and images are properly enhanced by Erdas Imagine software.

\subsection{Normalized Difference Vegetation Index}

Basically, NDVI is a vegetation index which indicates the appropriate vegetation health condition of an area. NDVI values always stand in between $(+1)$ and $(-1)$ (Fig. 3a). 

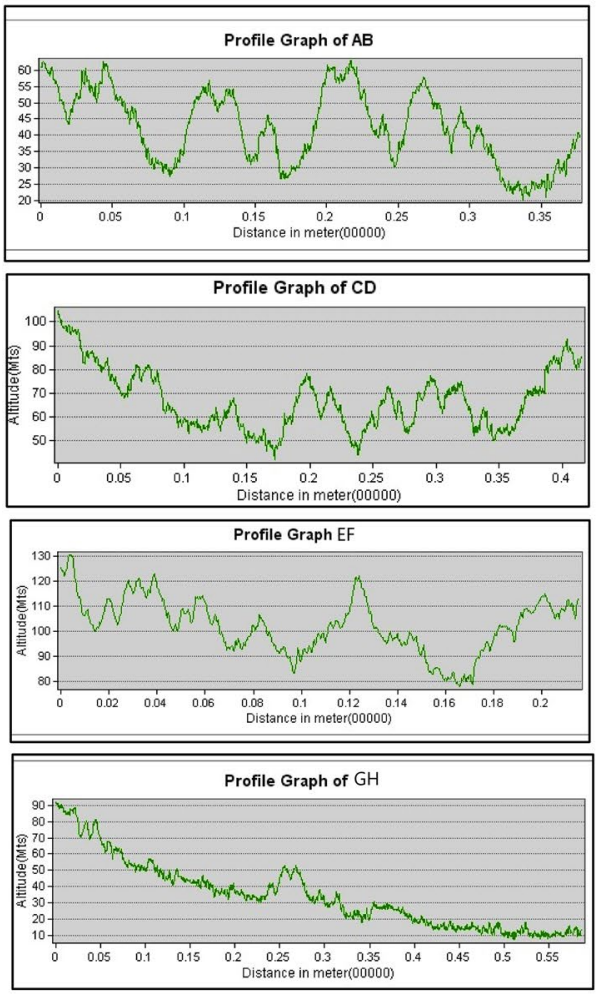

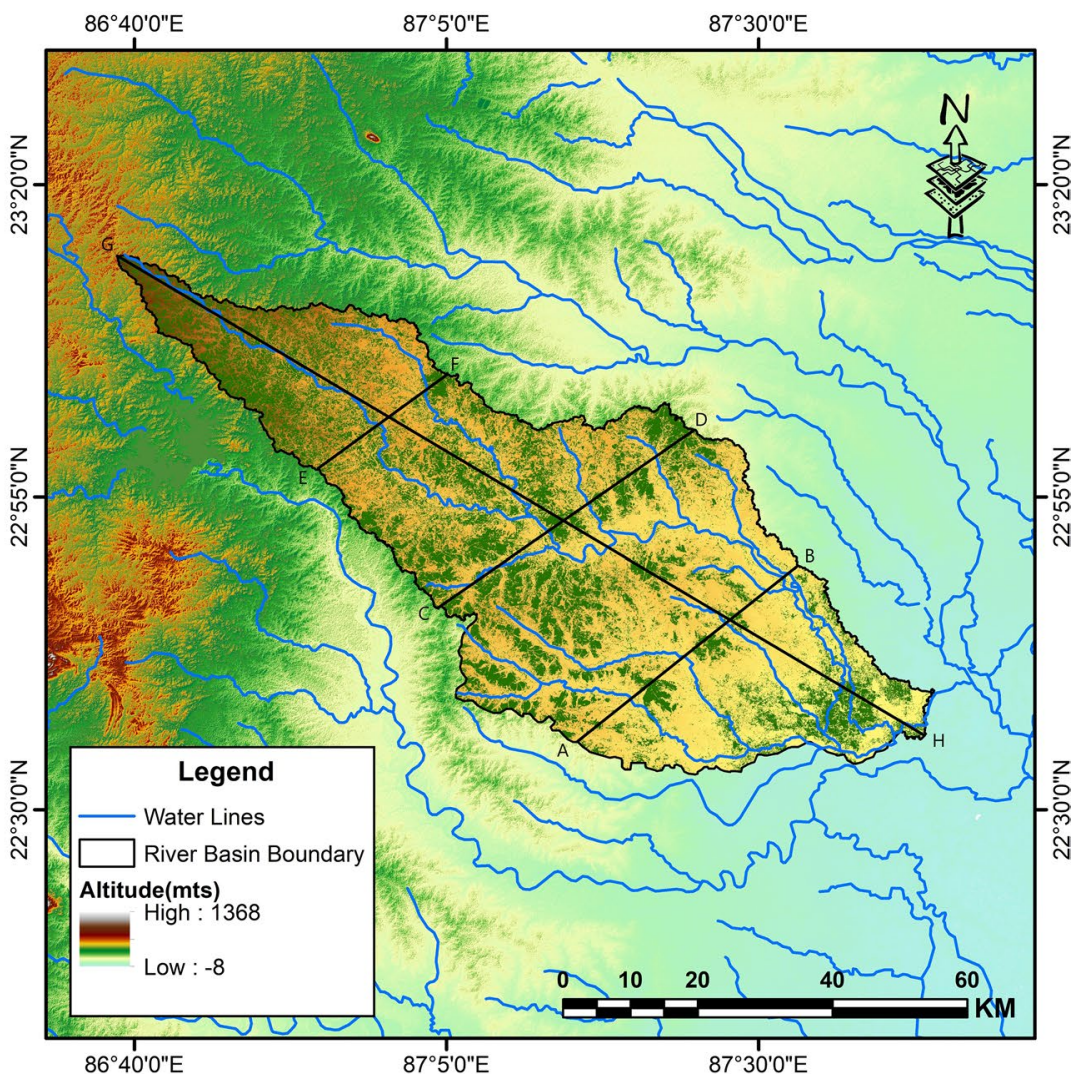

Fig. 2 Cross-sections demonstrate about the topographic expression of different parts of Silabati river basin

Table 1 Details of the used satellite images

\begin{tabular}{llllllll}
\hline Landsat & Sensor & Date of acquisition & $\begin{array}{l}\text { Spatial resolu- } \\
\text { tion }(\mathrm{m})\end{array}$ & Sun azimuth & Sun elevation & Path & Row \\
\hline 8 & OLI & 1 Oct 2019 & 30 & 139.4952 & 56.7578 & 139 & 044 \\
5 & TM & 10 Oct 1998 & 30 & 136.9450 & 51.2792 & 139 & 044 \\
5 & TM & 12 Oct 2009 & 30 & 150.2927 & 43.9112 & 139 & 044 \\
\hline
\end{tabular}

Higher value indicates better vegetation health on the contrary low value specifies poor vegetation health and in general +0.4 represents good condition of vegetation growth. NDVI index was first used by Rousel in (1974) to determine the health and growth of the vegetation in a particular area. The most common and widely used vegetation index is NDVI which detects the vegetative areas over a region (Bhandari and Kumar 2012). Differences between red band and infrared band are also used to calculate NDVI values over an area (Gandhi 2015):

$\mathrm{NDVI}=\frac{(\mathrm{NIR}-\mathrm{Red})}{(\mathrm{NIR}+\mathrm{Red})}$

\subsection{Shadow Index}

Canopy shadow index is a vital spectral index which provides the essential information about forest canopy cover. SI index examines the total reflectance from the canopy cover. High SI value indicates mature or dense forest while low value implies open forest or comparatively less forest covered areas (Fig. 3b). FCD model is also used to find out the actual canopy cover whereas SI index also calibrates the total reflectance through the canopy of the forest (Huemmrich 1996):

SI $=[(1-\text { Red }) \times(1-\text { Green }) \times(1-\text { Blue })]^{1 / 3}$. 

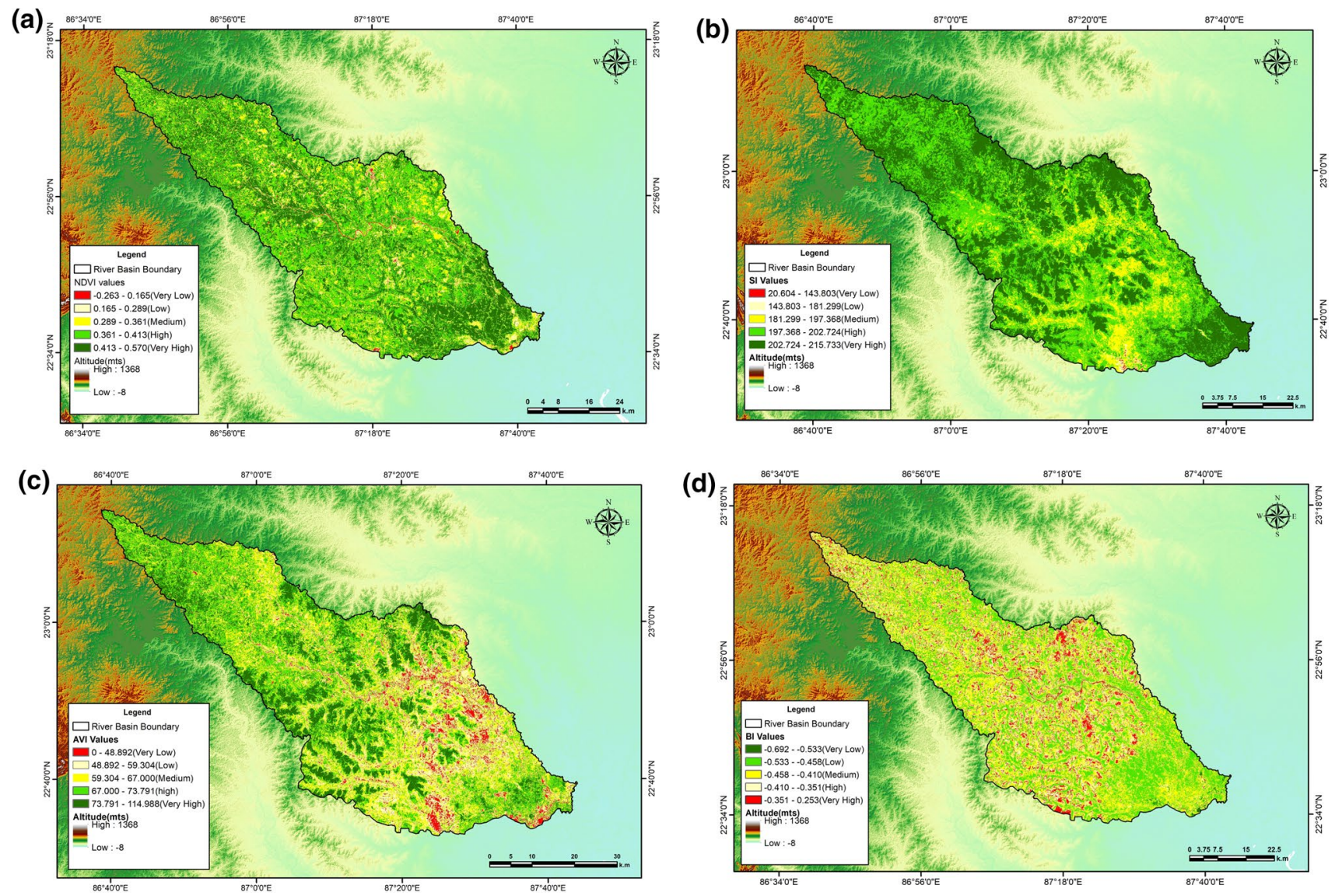

Fig. 3 Different thematic layers of spectral indices, a Normalized Difference Vegetation Index, b Shadow Index, c Advanced Vegetation Index, and $\mathbf{d}$ Bareness Index

\subsection{Advanced Vegetation Index}

Advanced Vegetation Index is another important spectral reflectance index which provides us to extract vegetation condition from a multi-spectral image which is similar to NDVI. Two different types of spectral bands (red and infrared bands) are used to classify the vegetation conditions through spectral reflectance values (Fig. 3c). AVI is more sensitive than NDVI to resolve the high canopy areas. There is a minimal difference between NDVI and AVI, which is enhanced using a power degree (Roy et al. 1996). There is a subtle difference between NDVI and AVI, and the vegetation foliage activity is also extracted by AVI index (Anonymous 1993):

$\mathrm{AVI}=\left[(\mathrm{NIR}+1(1-\mathrm{Red}) \times(\mathrm{NIR}-\mathrm{Red})]^{1 / 3}\right.$.

\subsection{Soil Bareness Index}

Bare land means the virgin land represents zero anthropogenic action within the given geological time frame. Bareness Index is also called a spectral reflectance index which shows the condition of soil or land of an area (Fig. 3d). Primarily, it has been used as a cropland indicator. Bare land could be classified into two different categories viz. primary bare land which has no human imprints while secondary bare land has high and low degree of anthropogenic signature (Pal et al. 2018). Four different spectral bands have been considered such as blue, red, near infrared and short wave infrared to identify the degree of bareness. Mineral composition of the soil is represented by the short-wave infrared and red bands whereas near-infrared and blue bands have been used to represent the vegetation condition. Bare soil index also indirectly reflects that how much forest canopy cover is there in a specific time span (Rikimaru and Miyatake 1997). Bareness soil index (BSI) is calculated through the following equation: 
BSI $=\frac{(\text { Band6 }+ \text { Band } 4)-(\text { Band } 5-\text { Band } 2)}{(\text { Band6 }+ \text { Band } 4)+(\text { Band5 }+ \text { Band2 })}$

where $\mathrm{B}$ and 2 reflectance value of blue band, Band $4=$ reflectance value of red band, Band $5=$ reflectance value of infrared band, Band6 $=$ reflectance value of shortwave infrared band.

\subsection{FCD Model}

Forest Canopy Density model is a key tool to quantify the forest density of an area (Sahana et al. 2015). By applying this model, it is easily determined that how much forest areas have either been deforested or degraded. Subsequently, the FCD map has been designed by weightage overlay analysis techniques using Arc Gis (10.3) software, and finally, all the above-mentioned indices are integrated to prepare the final output of Silabati river basin (Fig. 5).

\subsection{Use of Maximum Likelihood Classifier for LULC Classification}

The word Land use and Land cover is an important physical and anthropogenic variable on the surface of the earth. Land use means the anthropogenic use of land and land cover means the natural encircle or various attributes over the earth surface. Due to rapid rate of population explosion along with execution of different developmental projects, the land-use and land cover patterns have been tremendously changed over the time. Detection of the patterns of land-use and land cover change gives us an ample scope to implement sustainable management plan. This model is widely applied in different fields such as climate change and its impact on forest, disaster prediction, forest degradation, forest land conversion, and settlement growth within forest tract (David et al. 2016). Most popular classification methods are extensively used such as supervised classification, unsupervised classification, parametric and non-parametric classification, and hard and soft classification (Fuzzy classification).
Different methods such as Maximum Likelihood, $k$-means classifier, ISODATA classifier, and spectral mapping classifier are used in case of supervised classification ( $\mathrm{Lu}$ and Weng 2007) and among these classification methods, the Maximum Likelihood classifier is the most accepted and rational classification technique.

\subsection{Forest Fragmentation Approach}

In the recent years, forest habitats are being fragmented due to multiple reasons in different parts of the world. Now different methods have been discovered to quantify in spatiotemporal extensions of the earth. In this method, forest area has been classified into four different zones such as Patch, Perforated, Edge and Core along with 100-m edge width. Centre for Land Use Education and Research (CLEAR) developed the fragmentation tool (LFT) with version 2.0. This spatial analysis tool also classified the raster forest data into four different categories, viz., Patch, Edge, Perforated and Core (Fig. 6). Further the core is also classified into three important classes such as high core ( $>500$ acre), medium core $(250-500$ acre) and low core $(<250$ acre $)$ areas.

\section{Result}

\subsection{Normalized Difference Vegetation Index (NDVI)}

NDVI is basically spectral index which denotes the vegetation health condition. In Silabati river basin, it has been found that NDVI value varies from -0.26 to +0.57 (Fig. 3a). The NDVI range has been further classified into five different classes. Each class has its own threshold value. Higher and very high-NDVI class is in between the value of $0.36-0.57$. High-NDVI values are found and dominated within the dense tropical deciduous forest. These dense forest pockets are identified here such as Gohaldanga Forest, Hoomgarh forest, Saringgarh forest, Arabari Forest, and
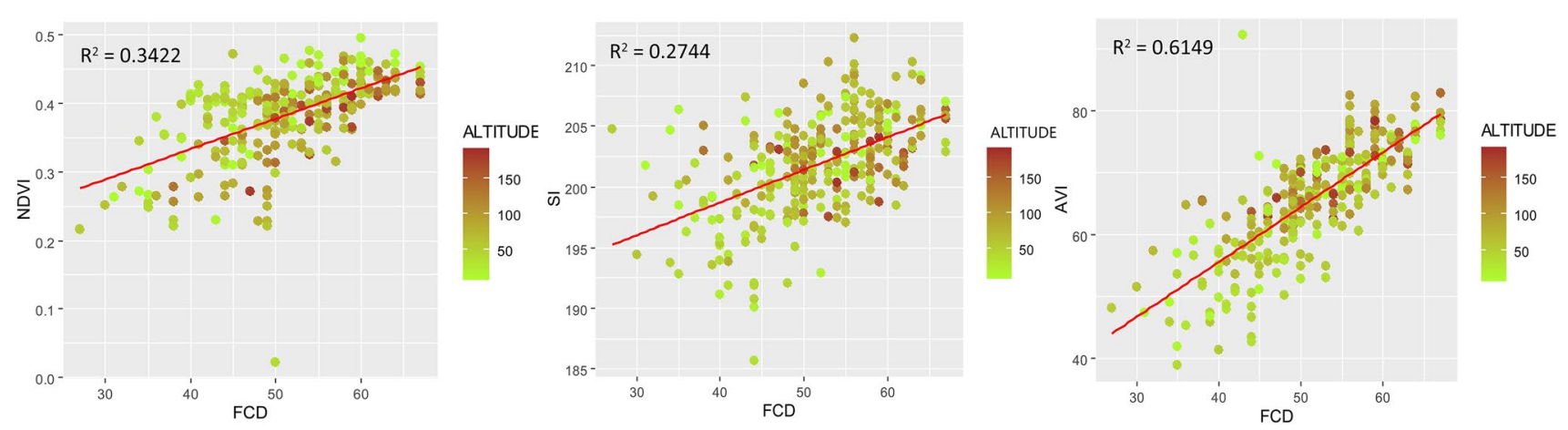

Fig. 4 Scatter plots show the relationship of different spectral indices with FCD values 


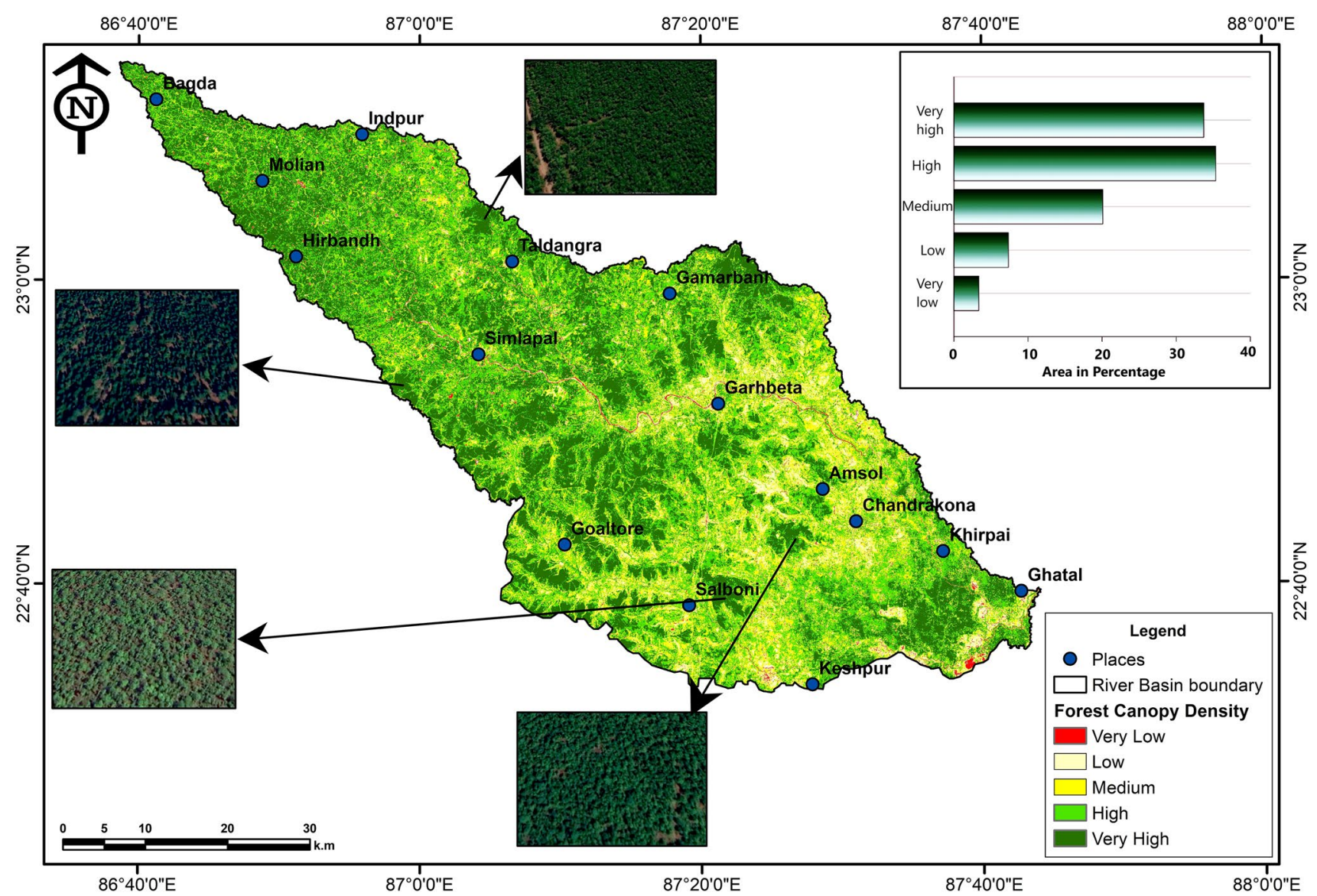

Fig. 5 Forest cover density map of Silabati river basin using FCD model

Table 2 Total area of different canopy density classes with percentage

\begin{tabular}{lc}
\hline Density class & $(\%)$ of area \\
\hline Very low & 3.36 \\
Low & 7.40 \\
Medium & 20.09 \\
High & 35.38 \\
Very high & 33.76 \\
\hline
\end{tabular}

Dhamkura scrub forest. Moderate NDVI value $(+0.28$ to +0.36 ) is concentrated over the upper and middle courses of the study area. It is observed from the ground that the medium value of NDVI is mostly occupied by scrubs and agricultural land. Low-NDVI values are mainly confined over the less vegetated areas of Silabati river basin while dominated areas show the bare land and water body. The regression analysis between NDVI and FCD also shows that they have a positive relationship with $R^{2}$ value 0.3422 (Fig. 4).

\subsection{Shadow Index (SI)}

Shadow Index is a spectral reflectance index which measures the canopy shadow effects on spectral reflectance curves. Mature forests have higher value of SI compared with the new forest areas. It has been observed that the SI value varies from 20.60 to 215.73 (Fig. 3b). The basin has been divided into five different SI classes. Each class has its own threshold value. High and very high SI values (197.36-215.73) are confined over the middle and lower section owing to dominancy of tropical deciduous forest (Arabari forest, Dhamkura forest range, and Hoomgarh range). Low and very low SI value (20.60-181.29) has chiefly been restricted in river networks, water body and exposed land areas. Remaining portion is under the medium SI value class (181.29-197.36). The Regression analysis between FCD and SI values also shows a positive relationship between them but the relation is relatively low with $\mathrm{R}^{2}$ value 0.2744 (Fig. 4). 
Table 3 Assigned weight of different classes of thematic layers

\begin{tabular}{lll}
\hline Theme & Classes & Weight \\
\hline NDVI & Very high & 5 \\
& High & 4 \\
& Medium & 3 \\
& Low & 2 \\
AVI & Very low & 1 \\
& Very high & 5 \\
& High & 4 \\
& Medium & 3 \\
BI & Low & 2 \\
& Very low & 1 \\
& Very high & 1 \\
& High & 2 \\
SI & Medium & 3 \\
& Low & 4 \\
& Very low & 5 \\
& Very high & 5 \\
& High & 4 \\
& Medium & 3 \\
& Low & 2 \\
& Very low & 1 \\
\hline
\end{tabular}

\subsection{Advanced Vegetation Index (AVI)}

AVI is also a spectral reflectance index which is similar to NDVI. But there is a minimal difference between AVI and NDVI. The AVI value range varies from 0.00 to 114.98 (Fig. 3c). Considering the threshold value, it has been further divided into five different classes. The lower part of the Silabati basin holds high and very high AVI values (67.00-114.98) because of higher concentration of dense deciduous forest. Middle course of the watershed has low and very low AVI values (0.00-59.30) due to the presence of water body and fellow land. The Regression analysis shows a positive relationship between AVI and FCD with $R^{2}$ value of 0.6149 (Fig. 4).

\subsection{Bareness Index (BI)}

$\mathrm{BI}$ is a spectral reflectance index. The bareness values of soil vary from -0.69 to +0.25 (Fig. $3 \mathrm{~d}$ ). The total basin area has been further classified into five different classes; each class has its own threshold value which discriminates a class from other class. In Silabati river basin, the water body, river channel and exposed land indicate high and very high bareness value $(-0.41$ to +0.25$)$ that is spread over middle and isolated patches of upper part of the basin. Agricultural land and forest areas give low to very low BI values $(-0.69$ to -0.45$)$ which is concentrated over the middle and lower courses that are also covered by tropical deciduous forest. Rest of the areas come under medium BI value classes $(-0.48$ to -0.41$)$.

\subsection{Forest Canopy Density Model (FCD)}

Forest Canopy Density model of Silabati river basin has been prepared through the amalgamation of four different indices such as Normalized Difference Vegetation Index (NDVI), Advanced Vegetation Index (AVI), Bareness Index (BI) and Shadow Index (SI). Weightage Overlay Analysis method has been applied to get high precision outputs (Fig. 5). On the basis of their relative significance, weights are assigned to different themes and classes of themes (Tables 3 and 4). The five classes have been done based on FCD values which range from very low to very high. The middle course and the lower middle courses contain high and very high forest cover due to ideal environmental conditions for their growth within given study area. The upper course of the basin has undulating plateau that contains medium to low canopy density along with scatter open forest. In the Silabati basin, around 3.36, 7.40, 20.09, 35.38 and $33.76 \%$ geographical areas are under non-forest, low canopy density, medium canopy density, high canopy density and very high-density forest, respectively (Table 2). High canopy density areas generally enclose by tropical deciduous forest which contains teak, Sal, jackfruit, arjun, and palash trees. The agrarian fields and bare land shows medium to low FCD value. This model is very rational and scientific to quantify the forest canopy cover as well as forest health (Tables 3, 4).

\subsection{Forest Condition Status During 1998-2019}

Forest fragmentation map (1998) showed (Fig. 6a) that the core area has concentrated in the lower and central part of Silabati river basin due to less human intervention. This core

Table 4 Normalization procedure for different class weights of thematic layers

\begin{tabular}{lllllll}
\hline Theme & NDVI & AVI & BI & SI & Mean & Normalized weight \\
\hline NDVI & $5 / 5$ & $5 / 4$ & $5 / 3$ & $5 / 2$ & 1.5106 & 0.3776 \\
AVI & $4 / 5$ & $4 / 4$ & $4 / 3$ & $4 / 2$ & 1.2085 & 0.3021 \\
BI & $3 / 5$ & $3 / 4$ & $3 / 3$ & $3 / 2$ & 0.9064 & 0.2266 \\
SI & $2 / 5$ & $2 / 4$ & $2 / 3$ & 0.6042 & 0.1510 \\
\hline
\end{tabular}



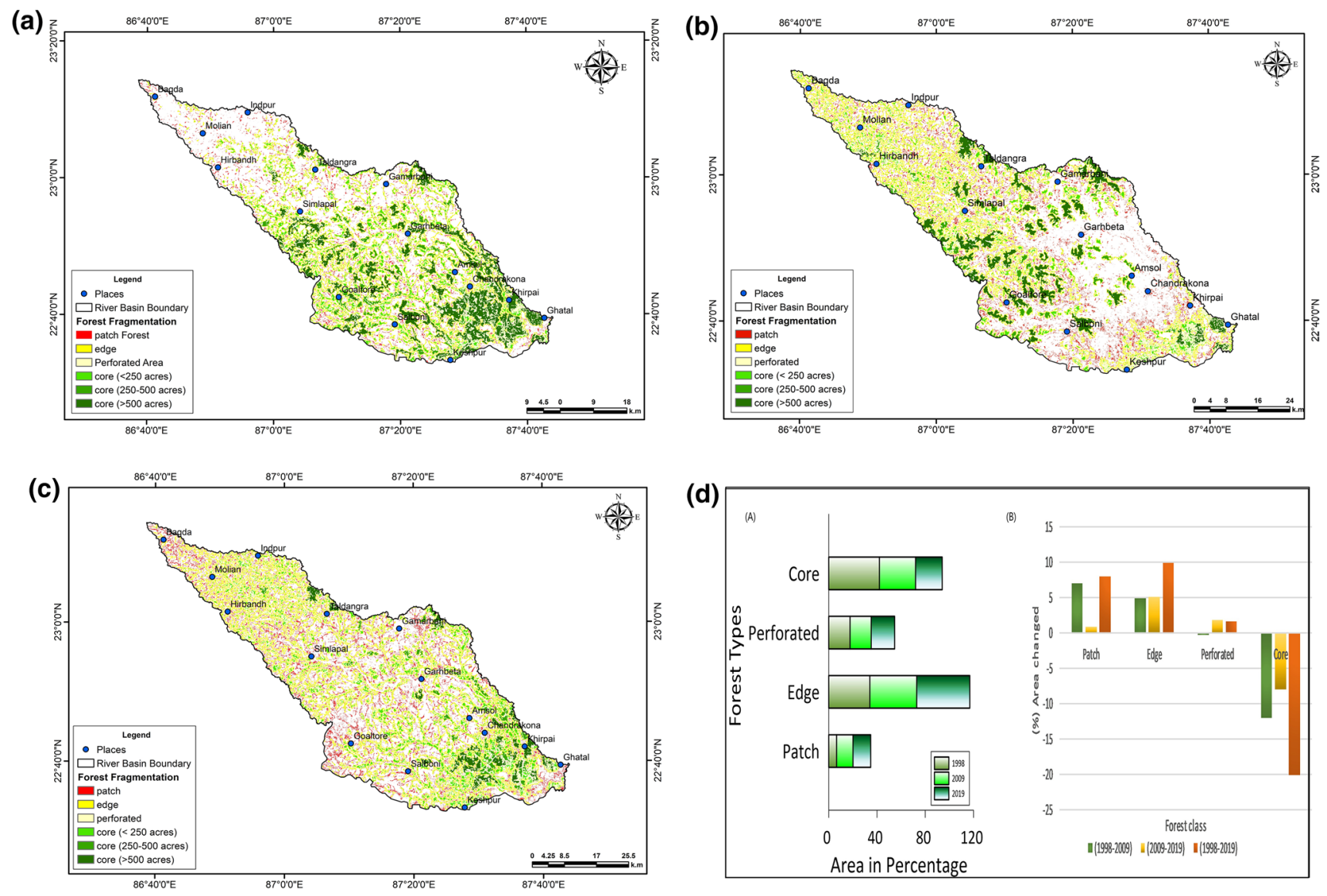

Fig. 6 Forest fragmentation map of different years. a Fragmentation map of 1998, b fragmentation map of 2009, and c fragmentation map of 2019

area consists of deciduous forests ranges while Sal (Shorea robusta) is the dominated deciduous species in this region. In 1998 , it has been observed that $42 \%$ area is under core forest region, $6.51 \%$ patch, $34.02 \%$ edge and $17.64 \%$ perforated areas. The core forest zone covers middle and lower middle courses of the river basin. In 2009, patch forest has been identified in the upper and central sections of the basin. Approximately, $30 \%$ forest cover area is under the core forest area, and 13.61, 38.89 and $17.57 \%$ areas are under patch, edge and perforated forest areas, respectively (Fig. 6b). The forest fragmentation map of Silabati river basin (in 2019) is highlighted that the core zone has concentrated in the lower middle and also some parts of middle course of the basin. In 2019 , the areas of edge and patch forest have slightly increased. Edge forest contains $43.97 \%$ area of total forest area and core forest contains $22.02 \%$ (20\% loss with respect to 1998) of total forest area, this is a negative indicator of sustainable management and sustainable forest management policies are required. Patch forest and perforated forest have contained 14.62 and $19.37 \%$ forest areas, respectively (Fig. 6c, Table 5).

\subsection{LULC Condition Status During the Study Period 1998-2019}

In the years 1998, 2009 and 2019, the Silabati river basin area has been classified into five different LULC classes, viz., vegetation, agricultural land, sand bar, river and water body and settlement. In 1998, forest area has concentrated in the middle and lower courses of the basin that has occupied $41.59 \%$ area of the total basin. Agricultural land has contained highest percentage of area; it has occupied around $54.42 \%$ area of total Silabati river basin in 1998 that is ascertained that in 1998, the Silabati river basin was agriculturedominated area. The other classes are sand bar, river and water body, and settlement, that has enclosed around 0.16, 1.72 and $3.12 \%$, respectively (Fig. 7a, Table 7). In 2009, it has been noticed that the agricultural land has occupied around $1920.73 \mathrm{~km}^{2}$ or about $56.44 \%$ with respect to total basin area. There was an indication of agricultural dominancy in Silabati river basin in the year 2009. Vegetal cover has occupied $1285.02 \mathrm{~km}^{2}$ or around $37.76 \%$ with respect to total river basin. The others attributes such as sand bar, river and water body and settlement have comprised by $0.13,1.31$ 
Table 5 Types of forest fragmentation classes with respective areas in percentage

\begin{tabular}{llll}
\hline Forest types & 1998 & 2009 & 2019 \\
\hline Patch & 6.515 & 13.613 & 14.620 \\
Edge & 34.025 & 38.898 & 43.972 \\
Perforated & 17.648 & 17.575 & 19.376 \\
Core & 42 & 30 & 22.02 \\
\hline
\end{tabular}

and $4.37 \%$, respectively (Fig. 7b, Table 7). In 2019, agricultural land has occupied $1667.32 \mathrm{~km}^{2}$ areas that are $49.16 \%$ with respect to total basin area. Vegetation has contained $1465.05 \mathrm{~km}^{2}$ that is $43.19 \%$ of total basin area and vegetation cover concentrates over lower part and a little upper part of the basin whereas settlement, sand bar, river and water body has contained $5.68,0.24$ and $1.73 \%$ areas, respectively (Fig. 7c, Table 7).

\section{Discussion}

\subsection{Forest Habitat Fragmentation Scenario}

Forest fragmentation is the process or mechanism where continuous or grandiose forest land is converted into small segments or isolated forest regions. In the recent years, forests are being split due to human-induced land-use change. Expanding human pressure over nature and anthropogenic stress over natural resources degrades the health of the forest cover which is the principal reason of forest fragmentation

Table 6 Changes of forest fragmentation (\%) in different time period (from 1998 to 2019)

\begin{tabular}{lccc}
\hline Forest types & $(1998-2009)$ & $(2009-2019)$ & $(1998-2019)$ \\
\hline Patch & 7.097 & 1.007 & 8.105 \\
Edge & 4.873 & 5.073 & 9.947 \\
Perforated & -0.073 & 1.801 & 1.727 \\
Core & -12 & -7.98 & -19.98 \\
\hline
\end{tabular}
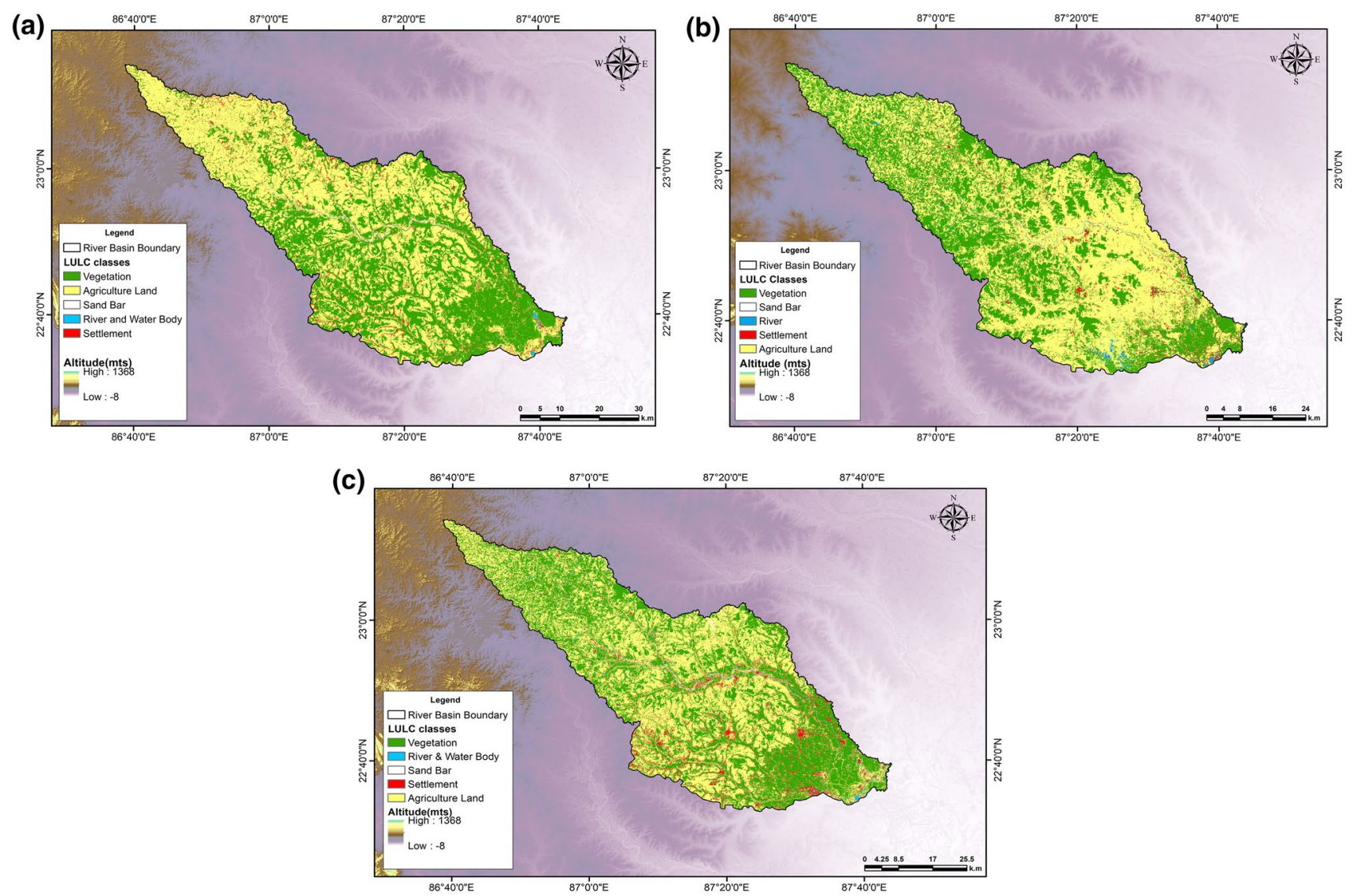

Fig. 7 Land-use land cover map of different years. a LULC map of 1998, b LULC map of 2009, and c LULC map of 2019 
and it expands the research area of landscape ecologist (Whitmore 1997; Liu and Taylor 2002; Roy et al. 2013). Roads, agricultural land and urbanization have segmented the forests into several parts; these curtail the impotence of forest land over earth natural environment. Degraded forest has a negative effect over biodiversity (Roy and Tomar 2000; Jetz et al. 2007). Emergence of RS and GIS software became a useful tool for examining forest management and human-induced forest fragmentation with a high accuracy rate (Wilkie and Finn 1996; Haila 1999). Different types of hyper- and multi-spectral images help us to audit the accurate fragmentation data and to enumerate the forest fragmentation rate in a particular area. In addition, this type of remote sensing-based forest fragmentation approach helps the government to implement the proper forest policy and sustain the proper management programs (Reddy 2013; De and Tiwari 2008; Vogt et al. 2007). Forest fragmentation model has been applied on Silabati river basin considering different time span. High spatial resolution Landsat data (30 mts) have been used to enumerate the actual forest fragmentation scenario and the degradation rate. It has been observed that there is a change of forest area during time period of 1998-2019. Primarily, the forest of Silabati river basin has been classified into four classes-patch forest, edge, perforated and core while core is also subdivided into three parts, high-core area, middle-core area and low-core area. Core forest also indicates the dense forest which is not yet disturbed by any anthropogenic action. Patch forest is also a fragmented forest habitat that is broken down due to anthropogenic interferences.

\subsubsection{Assessment of Forest Fragmentation During the Period 1998-2019}

In global point of view, societal development has a negative impact on environment as well as forest regions and forest is being fragmented due to execution of some developmental projects such as road construction, building and multiplex construction, construction of railway, and extension agricultural land (Southworth et al. 2004; Bera et al. 2020). Unexpected population growth along with various anthropogenic activities mainly in tropical and sub-tropical regions carry fast change of LULC and this human-induced land-use change creates conflict over a forest region (Dutta et al. 2017). Forest fragmentation has a relation with habited loss that is exceptionally related to biodiversity loss in a region (Fahrig 2003). In 1998, it has been observed that around $1404.579 \mathrm{~km}^{2}$ areas are under forest cover of Silabati river basin that is $41.58 \%$ area with respect to total river basin. In 2009, around $1285.09 \mathrm{~km}^{2}$ areas $(37.76 \%$ ) are under forest. The year 2019 showed that the forest covered was around $1465.05 \mathrm{~km}^{2}$ that is $43.19 \%$ with respect to total basin area (Table 7). It seems that the total $116.549 \mathrm{~km}^{2}$
Table 7 Different land-use and land cover classes with respective areas in percentage

\begin{tabular}{lrrr}
\hline LULC classes & \multicolumn{1}{c}{2019} & \multicolumn{1}{c}{2009} & \multicolumn{1}{c}{1998} \\
\hline Vegetation & 43.193 & 37.757 & 41.586 \\
Settlement & 5.679 & 4.367 & 3.118 \\
Agricultural & 49.157 & 56.435 & 54.418 \\
$\quad$ land & & & \\
$\begin{array}{l}\text { Sand bar } \\
\begin{array}{l}\text { River and water } \\
\text { body }\end{array}\end{array}$ & 0.239 & 0.127 & 0.158 \\
\hline
\end{tabular}

(3.829\%) areas have been degraded during 11 years period (1998-2009) with a rate of about $10.59 \mathrm{~km}^{2} /$ year. There was a negative tendency as well as unpleasant indication for physical environment and specially biodiversity. Meanwhile, it has been observed that in 2019 , around $180.02 \mathrm{~km}^{2}$ (5.43\%) forest areas have been regained from 2009 with a rate of $18 \mathrm{~km}^{2} /$ year that is possible only due to implementation of forest policies specifically execution of participatory forest management techniques. In both the years, the forest has been categorized into four different classes such as patch, edge, perforated and core and the core class is also subdivided into three different classes, high core, middle core and low core (Fig. 6). It has been observed that in $1998,91.31 \mathrm{~km}^{2}(6.51 \%), 476.9 \mathrm{~km}^{2}(34.03 \%), 247.36 \mathrm{~km}^{2}$ $(17.65 \%)$ and $586 \mathrm{~km}^{2}(42 \%)$ areas are under patch, edge, perforated and core forests, respectively (Table 5). The high percentages of core forest areas indicate low anthropogenic stress over natural resources. It has been executed that in 2009, around $174.93 \mathrm{~km}^{2}$ (13.61\%), $499.85 \mathrm{~km}^{2}$ (38.89\%), $225.84(17.57 \%)$ and $384.41(30 \%)$ areas are under patch, edge, perforated and core areas respectively. During the study period (1998-2009), it has been observed that patch forest area has increased $83.62 \mathrm{~km}^{2}(7.097 \%)$ area due to continuous human encroachment over forest. Edge region has increased $22.95 \mathrm{~km}^{2}(4.87 \%)$ whereas perforated areas have decreased $21.52 \mathrm{~km}^{2}(0.07 \%)$. There is the high down fall of core area in 2009 with respect to 1998, and total $201.59 \mathrm{~km}^{2}(12 \%)$ core area has decreased in 2009 (Table 6), with a rate of $18.32 \mathrm{~km}^{2} /$ year due to high anthropogenic interference over the forests in the basin area. Further, it has been portrayed that in 2019 , around $214.2 \mathrm{~km}^{2}(14.62 \%)$, $644.22 \mathrm{~km}^{2}$ (43.97\%), $283.87 \mathrm{~km}^{2}(19.37 \%)$ and $322.76 \mathrm{~km}^{2}$ $(22.02 \%)$ areas are under patch, edge, perforated and core areas, respectively. During the study period (2009-2019), it has been further observed that in 2019, patch forest has increased $39.27 \mathrm{~km}^{2}(1.007 \%)$ with a rate of $3.92 \mathrm{~km}^{2} /$ year. Edge class has increased $144.37 \mathrm{~km}^{2}(5.07 \%)$ with a rate of $14.43 \mathrm{~km}^{2} /$ year. Perforated forest has increased $58.03 \mathrm{~km}^{2}$ $(1.80 \%)$ with a rate of $5.80 \mathrm{~km}^{2} /$ year but core forest has decreased $61.65 \mathrm{~km}^{2}(7.98 \%)$ with a rate of $6.16 \mathrm{~km}^{2} /$ year. 


\subsection{Land-Use and Land Cover (LULC) Scenario}

Detection of Spatiotemporal changes of LULC helps us to apply different policy and sustainable utilization of resources. Now days, many researchers bring off their attention to observe the land-use and land cover change detection in different parts of the world. Most of the unplanned land-use and land cover changes are the result of different unplanned and unscientific human-induced activities and this makes ecosystem of the region more fragile and vulnerable (Chamling and Bera 2020a). The excessive anthropogenic stress in the tropical and sub-tropical forest regions

Table 8 Land-use and land cover change in percentage in different time interval during (1998-2019)

\begin{tabular}{lrcc}
\hline LULC classes & $(1998-2009)$ & $(2009-2019)$ & $(1998-2019)$ \\
\hline Vegetation & -3.829 & 5.436 & 1.607 \\
Settlement & 1.249 & 1.312 & 2.561 \\
Agriculture land & 2.018 & -7.278 & -5.260 \\
Sand bar & -0.031 & 0.112 & 0.081 \\
River and water body & 0.593 & 0.416 & 1.009 \\
\hline
\end{tabular}

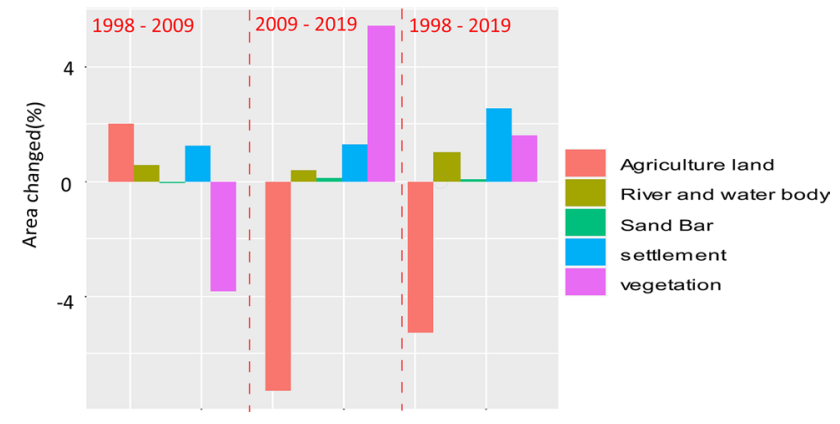

Fig. 9 Bar graph shows the magnitude of land-use land cover change (from 1998 to 2019)

of the world is the principal reason behind speedy decline of forestland and the number of regional biodiversity hotspots is escalating very fast due to large-scale wild habitat fragmentation and implementation of developmental projects (Chamling and Bera 2020b). Mainly, third world countries (tropical countries) are practicing high-intensive agricultural systems. The high population explosion, population pressure and implementation of different developmental activities within forest tract are the main driven forces of land-use
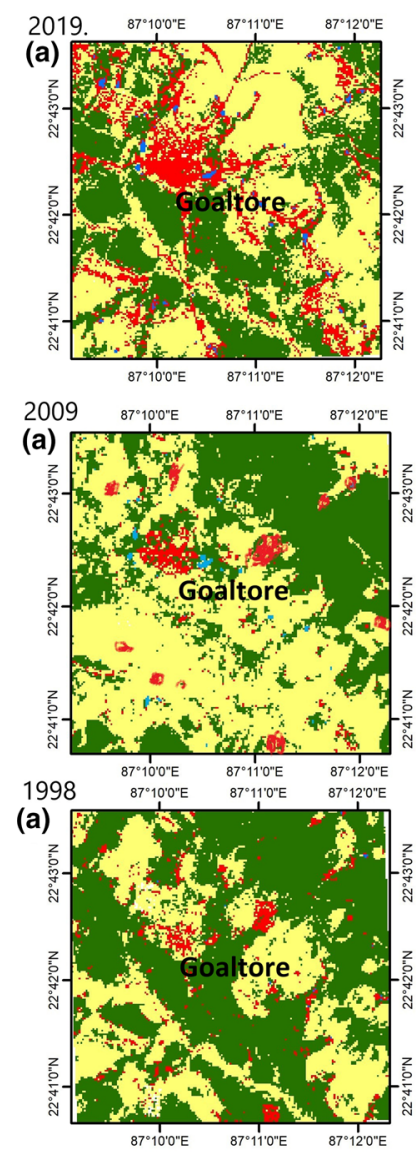

(b)
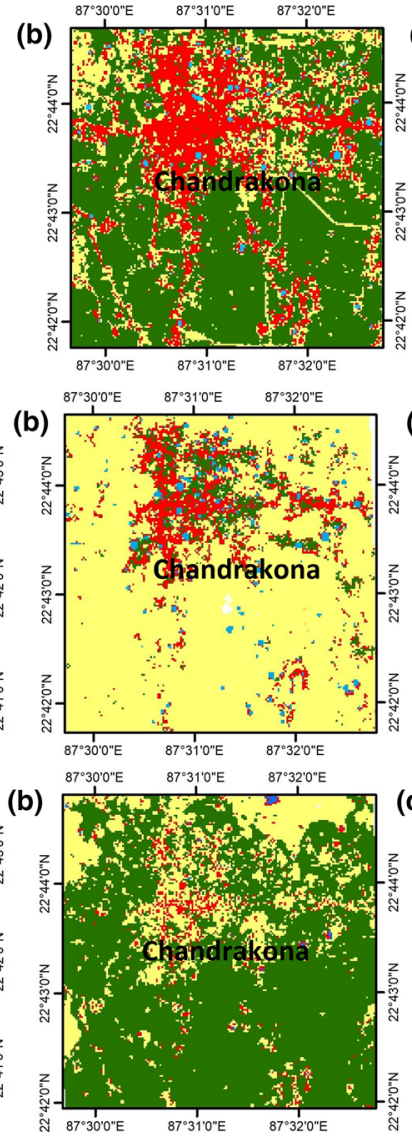

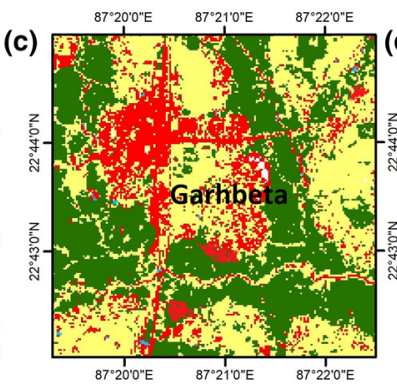

(c)
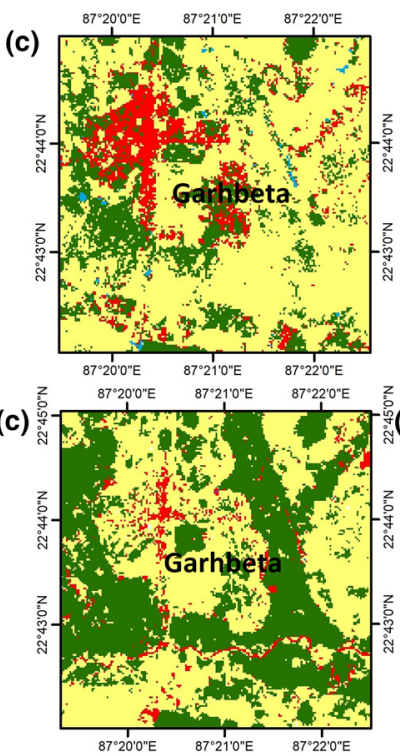
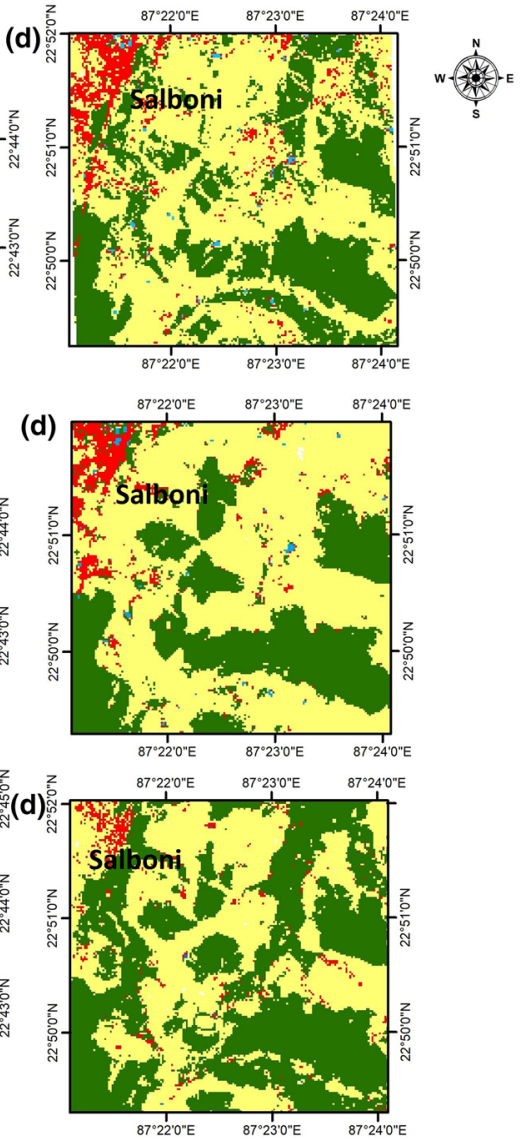

Fig. 8 Some identified hot spots areas within forest regions in Silabati river basin 
and land cover change (Goldewijk and Ramankutty 2004). Determination of the actual land-use land cover change using remote-sensing data is a significant aspect to observe the relationship among society, development and environment (Lu and Weng 2004; Fasona and Omojola 2005). Emergences of remote-sensing techniques are possible to detect the accurate change direction of land-use and land cover which has a significant impact on the society (Jensen 2007). Detection of the land-use and land cover change using multi-temporal satellite data is widely used to make suitable land-use planning and it encourages the landscape researchers of the world (Nelson 1983; Seto and Kaufmann 2005). The change detection of LULC provides valuable data and relevant information for proper environmental management and sustainable societal growth of mankind (Quintas-Soriano et al. 2016) (Table 7).

\subsubsection{The Assessment of LULC During the Period 1998- 2019}

The changing paradigm of LULC classes has been assessed during the study period (1998-2019) (Figs. 7, 9, Table 8). Here, vegetation recuperates around $71.18 \mathrm{~km}^{2}(1.607 \%)$ at a rate of $3.39 \mathrm{~km}^{2} /$ year that is a positive indication for health of the natural environment. But, it has been observed that vegetation cover is also depleted into the time period 1998-2009 but recovered in the year 2019 due to implementation of policies along with positive participation of local people through joint forest management program. According to the forest policy of 1998, different steps have been taken by the government of India such as afforestation, social forestry, and community forestry for sustainable forest management. West Bengal state government also applied these above-mentioned strategies in this region for better forest health and these strategies ultimately facilitate to regain the forest lands again. Remarkably, it is also noticed that agricultural land has decreased about $156.64 \mathrm{~km}^{2}$ (5.26\%) at a rate of $7.46 \mathrm{~km}^{2} /$ year. Another important thing is that settlement pockets have been enlarged around $88.13 \mathrm{~km}^{2}$ $(2.56 \%)$ at a rate of $4.20 \mathrm{~km}^{2} /$ year which indicates the over exploitation of natural resources due to excessive demand of population and it may cause large-scale forest fragmentation (Fig. 8). A sharp increasing trend has been observed in case of river and water body. A total of $34.53 \mathrm{~km}^{2}(1.009 \%)$ area (river and water body) has been increased from 1998 to 2019 due to excavation of ponds, canal and small-scale river channel avulsion (Fig. 9). The significant deforestation as well as fragmentation has been taken places (from 1998 to 2019) at the vicinity of the nodal growth centers such as Goaltore, Salboni, Garbeta, Chandrakona, Ghatal, and Keshpur. In the last two census years, population density along with infrastructural development has been increased tremendously in different urban areas and regional growth centers which have already been mentioned earlier. In the recent times, different developmental projects such as new road construction, community development centers, and Krishan Mandi have been executed by the State Government through clearing the forest pockets. Timber trafficking, poaching and forestland conversion are extensively amplified by the local people with the help of big illegal rackets in different pockets of Silabati river basin area. Meanwhile, according to 1988 forest policy, various strategies have been taken by state Government to ameliorate sustainable forest management well as to carry on good forest health. Social forestry, community forestry and farm forestry have been observed in different parts of the study area. Many forest dwellers are now the active members of joint forest management committee. Here, members take excellent initiative for protection of forest resources from illegal timber trafficking, large-scale tree failing and poaching while indirectly their dynamic participation improves environmental sustainability (Tisdell et al. 2001). As in the year 1981, West Bengal state had started social forestry project supported by World Bank, plantation and plant re-habitation were the foremost objectives of that project. Under that project, around 0.4 hectares of vegetated lands along with bare lands of Midnapur district of West Bengal state were allocated to poor people for tree plantation or crop cultivation. That project brought a fantastic result to regenerate new forest patches within given river basin. In Arabari community, forest range of West Midnapur district has become a first successful model of join forest management in India (Singh et al. 1999). According to national forest policy 1988, mainly tribal communities should be motivated to develop forest pockets. The scheduled tribes and other tribal dwellers act of 2006 gave a right to tribal people regarding the protection of biodiversity and simultaneously eco-friendly use of forest resources.

\section{Conclusions}

This geospatial application-based study is focused on existing canopy density and forest fragmentation (from 1998 to 2019) in Silabati river basin with the integration of four different indices such as Normalized Difference Vegetation Index, Advanced Vegetation Index, Shadow Index and Bareness Index. Higher NDVI, AVI and SI values indicate the higher forest canopy density on the contrary higher BI value indicates the low forest cover. A few central pockets and also the lower central course of the basin represent high FCD values due to the existence of a number of protected and reserve forests such as Arabari, Ghagra, Patharmari, Barasol, Rangametia, Garbeta, Murgasole, and Damodarpur. Similarly, scatter forest ranges are also situated at the upper course of the basin such as Simul Kundi, Amjhuria, Chenchurya, and Saharghati. According to forest survey 
report 1985, Sal (Shorea robusta) is the dominated species in the middle and lower sections of the river basin. Another associated species are Pterocarpus marsupium, Terminalia tomentosa, Bombax ceiba, Adina cordifolia, and Buchanania latifolia. Subsequently, the forest report 1985 clearly states that around $28.03 \%$ area was under open scrub which is confined in the lower course of the basin. From this integrated research work, it is affirmed that anthropogenic stress is principal regulating factor for forest habitat fragmentation and degradation particularly Silabati river basin. Consequently, it is identified that patch forest area has been increased $(8.105 \%)$ and some patch forest areas have been converted into human settlement area. The core forest has been degraded (19.98\%) at a higher rate during the period of 1998-2019. In the year 1998, the total forest cover area was $41.82 \%$ while the area is reduced by $3.829 \%$ in 2009 and in the year 2019, it has been further amplified by $5.436 \%$ due to implementation of some forest policies (such as joint forest management and community forestry.). Similarly, another important LULC aspect like water body (1.009\%) has been slightly increased due to excavation of ponds, canal and small-scale river channel diversion in different pockets of lower course of the river basin. The area of human settlements has been amplified by $2.561 \%\left(88.23 \mathrm{~km}^{2}\right)$ during the study. The population explosion along with rapid settlement growth influences the high likelihood of deforestation as well as forest fragmentation in the middle and lower part of the river basin. In the recent years, people desire to practice different types of cash crops such as oil seed and pulses, along with animal husbandry which expands the high rate of deforestation at the vicinity of regional growth centers. The huge anthropogenic stress in tropical and sub-tropical forest regions can modify the pristine forest cover scenario through the evolution of time. More research and development is required to bring the accuracy of these above-mentioned models although such models have been successfully applied in the different parts of the world. Administrators and policy makers should consider such research findings before making the policies for sustainable conservation of forest resources as well as balanced regional growth and development.

Open Access This article is licensed under a Creative Commons Attribution 4.0 International License, which permits use, sharing, adaptation, distribution and reproduction in any medium or format, as long as you give appropriate credit to the original author(s) and the source, provide a link to the Creative Commons licence, and indicate if changes were made. The images or other third party material in this article are included in the article's Creative Commons licence, unless indicated otherwise in a credit line to the material. If material is not included in the article's Creative Commons licence and your intended use is not permitted by statutory regulation or exceeds the permitted use, you will need to obtain permission directly from the copyright holder. To view a copy of this licence, visit http://creativecommons.org/licenses/by/4.0/.

\section{References}

Anonymous (1993) Rehabilitation of logged over forests in Asia/Pacific region. Final Report of Sub Project II International Tropical Timber Organization-Japan Overseas Forestry Consultants Association, pp 1-78

Azizi Z (2008) Forest canopy density estimating using satellite images. Int Arch Photogramm Remote Sens Spat Inf Sci 8(11):1127-1130. https://www.researchgate.net/publication/263901692_forest_ canopy_density_estimating_using_satellite_images

Beaulieu E, Lucas Y, Viville D, Chabaux F, Ackerer P, Goddéris Y, Pierret MC (2016) Hydrological and vegetation response to climate change in a forested mountainous catchment. Model Earth Syst Environ 2(4):1-15. https://doi.org/10.1007/s4080 8-016-0244-1

Bera B, Saha S, Bhattacharjee S (2020) Forest cover dynamics (1998 to 2019) and prediction of deforestation probability using binary logistic regression (BLR) model of Silabati watershed, India. Trees For People. https://doi.org/10.1016/j.tfp.2020.100034

Bhandari AK, Kumar A (2012) Feature extraction using normalized difference vegetation index (NDVI): a case study of Jabalpur city. Procedia Technol 6:612-621. https://doi.org/10.1016/j.protc y.2012.10.074

Chamling M, Bera B (2020a) Spatio-temporal patterns of land use/ land cover change in the Bhutan-Bengal foothill region between 1987 and 2019: study towards geospatial applications and policy making. Earth Syst Environ. https://doi.org/10.1007/s41748-02000150-0

Chamling M, Bera B (2020b) Likelihood of elephant death risk applying kernel density estimation model along the railway track within biodiversity hotspot of Bhutan-Bengal Himalayan Foothill. Model Earth Syst Environ. https://doi.org/10.1007/s40808-020-00849-z

Coppin PR, Bauer ME (1994) Processing of multitemporal Landsat TM imagery to optimize extraction of forest cover change features. IEEE Trans Geo Sci Remote Sens 32(4):918-927. https:// doi.org/10.1109/36.298020

Crist EP, Cicone RC (1984) Application of the tasseled cap concept to simulated thematic mapper data. Ann Arbor 1001-1007

David K, Yetta G, Agung F, Sharon H, Alison C (2016) Land use planning for disaster risk reduction and climate change adaptation: operationalizing policy and legislation at local levels. Int J Disaster Resil Built Environ 7(2):158-172. https://doi.org/10.1108/ IJDRBE-03-2015-0009

De A, Tiwari AK (2008) Estimation of patchiness: a measure of fragmentation in the Rajaji-Corbett National Parks and adjoining areas, Uttarakhand, India. Int J Ecol Environ Sci 34(4):345-349

Dolui G, Chatterjee S, Das Chatterjee N (2014) Weathering and mineralogical alteration of granitic rocks in Southern Purulia District, West Bengal, India. Int Res J Earth Sci 2(4):1-12. https://www. researchgate.net/publication/262564899_Weathering_and_Miner alogical_Alteration_of_Granitic_Rocks_in_Southern_Purul ia_District_West_Bengal_India

Dutta S, Sahana M, Guchhait S (2017) Assessing anthropogenic disturbance on forest health based on fragment grading in Durgapur Forest Range, West Bengal, India. J Spat Inf Sci 25:501-512. https ://doi.org/10.1007/s41324-017-0117-3

Fahrig L (2003) Effects of habitat fragmentation on biodiversity. Annu Rev Ecol Evol Syst 34:487-515. https://doi.org/10.1146/annur ev.ecolsys.34.011802.132419

Fasona MJ, Omojola AS (2005) Climate change, human security and communal clashes in Nigeria. In: Human security and climate change conference. https://doi.org/10.13140/2.1.2218.5928

Gandhi G (2015) Ndvi: vegetation change detection using remote sensing and gis - a case study of Vellore District. Procedia Comput Sci 57:1199-1210. https://doi.org/10.1016/j.procs.2015.07.415 
Ghosh S, Guchhait SK (2015) Characterization and evolution of laterites in West Bengal: implication on the geology of northwest Bengal Basin. Transactions 37(1):93-119

Goldewijk KK, Ramankutty N (2004) Land cover change over the last three centuries due to human activities: the availability of new global data sets. GeoJournal 61(4):335-344. https://doi. org/10.1007/s10708-004-5050-z

Guhathakurta P, Roy S (2000) Joint forest management in West Bengal: a critique. World Wide Fund for Nature India, New Delhi

Haila Y (1999) Islands and fragments in maintaining biodiversity in forest ecosystems. Cambridge University Press, Cambridge. https ://doi.org/10.1017/CBO9780511613029.009

Hasmandi MI, Pakhriazad HZ, Norlida K (2011) Remote sensing for mapping RAMSAR heritage site at Sungai Pulai Mangrove Forest Reserve, Johor, Malaysia. Sains Malaysiana 40(2):83-88

Huemmrich KF (1996) Effects of shadows on vegetation indices. In: IGARSS international geoscience and remote sensing symposium, Lincoln, NE, USA, vol 4, p 23722374. https://doi.org/10.1109/ IGARSS.1996.516990

Jelaska SD (2009) Vegetation mapping applications. Dev Soil Sci 33:481-496. https://doi.org/10.1016/S0166-2481(08)00021-4

Jensen JR (2007) Remote sensing of vegetation. In: Jensen JR (ed) Remote sensing of the environment: an earth resource perspective. Pearson Prentice Hall, Upper Saddle River

Jetz W, Wilcove DS, Dobson AP (2007) Projected impacts of climate and land-use change on the global diversity of birds. PLoS Biol 5(6): 157. https://doi.org/10.1371/journal.pbio.0050157

Kayet N, Pathak K, Chakraborty A, Sahoo S (2016) Spatial impact of land use/land cover change on surface temperature distribution in Saranda Forest, Jharkhand. Model Earth Syst Environ. https://doi. org/10.1007/s40808-016-0159-x

Lin Y (2014) Forest fragmentation and ecosystem function. In: Global forest fragmentation, chapter 8, pp 96-114

Liu J, Taylor W (2002) Integrating landscape ecology into natural resources management. Cambridge University Press, Cambridge. https://doi.org/10.1017/CBO9780511613654

Lu D, Weng Q (2004) Spectral mixture analysis of the urban landscape in Indianapolis with Landsat ETM + imagery. Photogram Eng Remote Sens 70(9):1053-1062. https://doi.org/10.14358/ PERS.70.9.1053

Lu D, Weng Q (2007) A survey of image classification methods and techniques for improving classification performance. Int J Remote Sens 28(5):823-870. https://doi.org/10.1080/01431160600746456

Mahala A (2019) Land degradation process of Silabati River Basin, West Bengal, India: a physical perspective, vol 15, pp 265-278

Maselli F, Conese C, De Filippis T, Norcini S (1995) Estimation of forest parameters through fuzzy classification of TM data. IEEE Trans Geosci Remote Sens 33(1):77-84. https://doi. org/10.1109/36.368220

Nelson RF (1983) Detecting forest canopy change due to insect activity using Landsat MSS. Photogram Eng Remote Sens 49(9):13031314. https://www.researchgate.net/publication/23593073_Detec ting_forest_canopy_change_due_to_insect_activity_using_Lands at_MSS

Pal SC, Chakrabortty R, Malik S et al (2018) Application of forest canopy density model for forest cover mapping using LISS-IV satellite data: a case study of Sali watershed, West Bengal. Model Earth Syst Environ 4:853-865. https://doi.org/10.1007/s4080 8-018-0445-x

Panta M, Kim M (2006) Spatio-temporal dynamic alteration of forest canopy density based on site associated factors: view from tropical forest of Nepal. Korean J Remote Sens 22(5):1-11

Quintas-Soriano C, Castro AJ, Castro H, García-Llorente M (2016) Impacts of land use change on ecosystem services and implications for human well-being in Spanish drylands. Land Use Policy 54:534-548. https://doi.org/10.1016/j.landusepol .2016.03.011

Raha AK, Sudhakar S, Prithviraj M (1997) Forest change detection studies and wetland mapping through digital image processing of Indian remote sensing satellite data

Reddy C (2013) Spatial patterns of forest fragmentation in Manipur, North-East India: a case study using RS and GIS techniques. Int J Earth Sci Eng 06(02):1713-1717. ISSN:0974-5904

Rikimaru A (1997) Development of forest canopy density mapping and monitoring model using indices of vegetation, bare soil and shadow. In: 18th Asian conference on remote sensing

Rikimaru A, Miyatake S (1997) Development of forest canopy density mapping and monitoring model using indices of vegetation, bare soil and shadow. In: 18th Asian conference on remote sensing, pp 20-24

Rouse JW, Haas RH, Scheel JA, Deering DW (1974) Monitoring vegetation systems in the great plains with ERTS. In: Proceedings, 3rd earth resource technology satellite (ERTS) symposium, pp. 48-62. https://ntrs.nasa.gov/citations/19740022614

Roy PS, Tomar S (2000) Biodiversity characterization at landscape level using geospatial modeling technique. Biol Conserv 95:95109. https://doi.org/10.1016/S0006-3207(99)00151-2

Roy PS, Sharma KP, Jain A (1996) Stratification of density in dry deciduous forest using satellite remote sensing digital dataan approach based on spectral indices, pp 723-734. https://doi. org/10.1007/BF02703148

Roy P, Murthy M, Roy A, Kushwaha S, Singh S (2013) Forest fragmentation in India. Curr Sci 00113891(105):774-780

Saei Jamalabad M, Abkar AA (2000) Vegetation coverage canopy density monitoring, using satellite images. In: ISPRS commission VII 17. Amsterdam, Holland

Sahana M, Sajjad H, Ahmed R (2015) Assessing spatio-temporal health of forest cover using forest canopy density model and forest fragmentation approach in Sundarban reserve forest, India. Model Earth Syst Environ 1(4):49. https://doi.org/10.1007/s4080 8-015-0043-0

Seto KC, Kaufmann RK (2005) Using logit models to classify land cover and land-cover change from Landsat Thematic Mapper. Int J Remote Sens 26(3):563-577. https://doi.org/10.1080/0143116051 2331299270

Shit P, Maiti R (2012) Rill hydraulics—an experimental study on gully basin in lateritic upland of Paschim Medinipur, West Bengal, India. J Geogr Geol. https://doi.org/10.5539/jgg.v4n4p1

Singh S, Agarwal S, Joshi PK, Roy PS (1999) Biome level classification of vegetation in western India-an application of wide field view sensor (WiFS). In: Proceedings of the joint workshop of ISPRS working groups I/1, I/3 and IV/4 sensors and mapping, pp 27-30

Southworth J, Munroe D, Nagendra H (2004) Land cover change and landscape fragmentation - comparing the utility of continuous and discrete analyses for a western Honduras region. Agric Ecosyst Environ 101:185-205. https://doi.org/10.1016/j.agee.2003.09.011

Tisdell C, Roy K, Ghose A (2001) Summaries of survey responses of household heads in three forest villages in the Midnapore District of West Bengal, India: use of forest resources by villagers, forest sustainability and management

Vogt P, Riitters KH, Estreguil C, Kozak J, Wade TG, Wickham JD (2007) Mapping spatial patterns with morphological image processing. Landsc Ecol 22:171-177. https://doi.org/10.1007/s 1098 0-006-9013-2

Wang Z, Brenner A (2009) An integrated method for forest canopy cover mapping using landsat ETM imagery. In: ASPERS/ MAPRS2009 fall conference 
Whitmore TC (1997) Tropical forest disturbance, disappearance, and species loss. In: Laurance

Wilkie DS, Finn JT (1996) Remote sensing imagery for natural resources monitoring: a guide for first-time users. Columbia University Press, New York. ISBN:023107929X, 9780231079297
Zhang X, Friedl MA, Schaaf CB, Strahler AH, Hodges JC, Gao F, Huete A (2003) Monitoring vegetation phenology using MODIS. Remote Sens Environ 84(3):471-475. https://doi.org/10.1016/ S0034-4257(02)00135-9 